\title{
VI. On the annular eclipse of the sun which will happen on the 15th of May 1836; being the principal results of calculations for Greenwich and Edinburgh
}

\section{Mr. George Innes}

To cite this article: Mr. George Innes (1821) VI. On the annular eclipse of the sun which will happen on the 15th of May 1836; being the principal results of calculations for Greenwich and Edinburgh , Philosophical Magazine Series 1, 58:279, 34-40, DOI: 10.1080/14786442108652558

To link to this article: http://dx.doi.org/10.1080/14786442108652558

$$
\text { 曲 Published online: } 27 \text { Jul } 2009 .
$$

Submit your article to this journal $\square$

$$
\text { Џlll Article views: } 3
$$


In all ruminating animals and birds of prey, there is a lucid tapetum at the bottom of the eye.

The owl, that never sees the sun, has no nigrum pigmentum.

The mackarel has the bottom of the eve lucid as quicksilver.

The coup de soleil, net with in the West Indies, the effects of which I have seen, I attribute to the scorching effect of the sun's rays upon the scalp.

The Egyptian ophthalmia I consider to te the effect of the sun's rays, and the glare of reflected light.

I have stated the fact of the scorching power of the sun's rays being destroyed when they are applied to black surfaces, but have not gone further. Sir Humphry Davy, to whom I showed these observations, immediately explained it. He said the radiant heat in the sun's rays was absorbed by the black surface, and converted into sensible heat.

VI. On the annular Eclipse of the Sun which will happen on the I5th of May 1836; being the principal Results of Calculations for Greenwich and Edinburgh. By Mr. George INNES.

Si _ T 18 Aberdeen, May 15, 1821.

SrR, - HE great solar eclipse of April 1, 1764, after four Chaldean periods, will return again on the 15 th of May 1836 . It will then be very great to all Europe, and in Great Britain jt will be more interesting than any that has happened since 1793 , as also than any that will happen before it. Like the eclipse of 1793; it will be annular in Scotland, but not at Greenwich.

The calculation of the general eclipse, the track of the central path of the annulus, its boundaries and extent, I shall reserve for a future communication. In the mean time, I send you the elements for projection and calculation, as also the results of the principal steps of calculations for Greenwich and Edirburgh.

1 once intended to send you the calculations at large, but after collecting the whole process into a quarto manuscript, I find that it could not be conveniently printed in octavo.

In making a projection of this eclipse for any particular place, it will be found that the times and digits eclipsed may be determined with almost as great accuracy as the method of projection admits of; the path of the moon, and those of the parallels of latitude, being nearly parallel to one another about the time of greatest obscuration; whereas in that of September last, they formed nearly the greatest angle possible.

The following elements are obtained from the Solar Tables of Delambre, and the Lunar Tables both of Burckhardt and Burg. In calculating for Greenwich and Edinburgh, $I$ have used the 'Tab!es of Burckhardt.

'The 
which will happen on the 15th of May 1836.

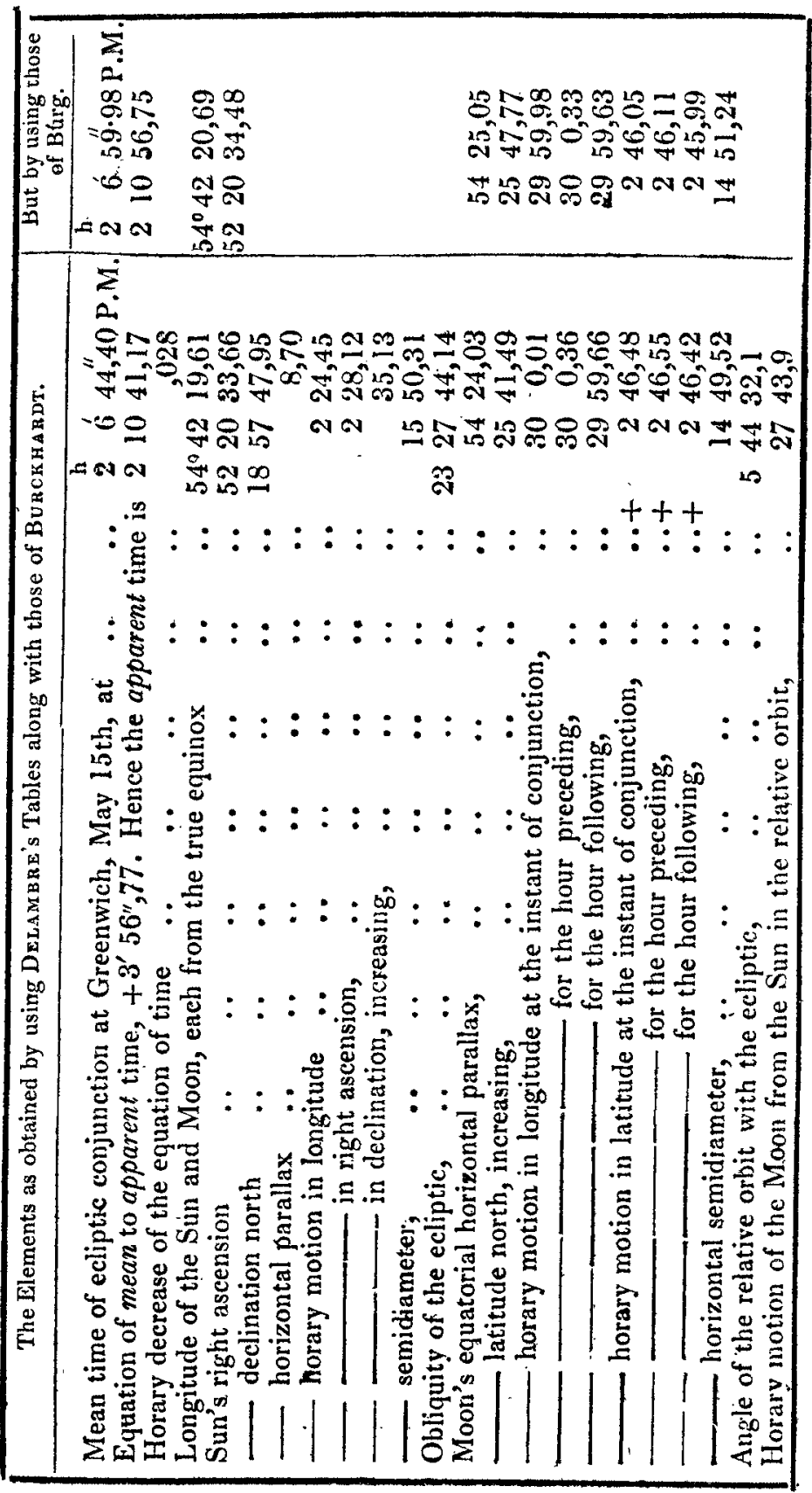


From the preceding Elements, as calculated from the Tables of Delambre and Burckhardt, the following data are obtained.

\begin{tabular}{|c|c|c|c|}
\hline Apparent time. & $\begin{array}{l}\text { D's hor. mot. } \\
\text { in long. }\end{array}$ & $\begin{array}{l}\text { 's s hor. mot. } \\
\text { in fong. }\end{array}$ & $\begin{array}{c}\text { s's } \\
\text { longitude. }\end{array}$ \\
\hline $\begin{array}{lll}0 & 10 & 41,226\end{array}$ & 5,61 & $15 \quad 2,805$ & 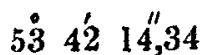 \\
\hline 04041,212 & 3,16 & 1,58 & 5357 \\
\hline $1 \quad 1041,198$ & 1,41 & 0,705 & $54 \quad 12 \quad 18$ \\
\hline $\begin{array}{lll}1 & 40 & 41,184\end{array}$ & 0,36 & 0,18 & $\begin{array}{lll}54 & 27 & 19,43\end{array}$ \\
\hline 21041 , & $\begin{array}{lr}30 & 0,01\end{array}$ & $\begin{array}{ll}15 & 0,005 \\
14 & 083\end{array}$ & $\begin{array}{lll}54 & 42 & 19,61 \\
5 & 57 & 1944\end{array}$ \\
\hline $\begin{array}{lll}2 & 40 & 41 \\
3 & 10 & 41\end{array}$ & $\begin{array}{ll}29 & 59,66 \\
29 & 58,61\end{array}$ & $\begin{array}{ll}14 & 59,83 \\
14 & 59,305\end{array}$ & $\begin{array}{lll}54 & 57 & 19,44 \\
55 & 12 & 18,745\end{array}$ \\
\hline 344 & 2956 & 1458,43 & \\
\hline 4 & 295 & 1457,205 & $42 \quad 14$ \\
\hline & 29 & 14 & $\begin{array}{llll}55 & 57 & 10,01\end{array}$ \\
\hline $\begin{array}{llll}5 & 10 & 41\end{array}$ & 2947 & & \\
\hline
\end{tabular}

Apparent time. $\mid D$ 's hor. mot. $D$ 's $\frac{1}{2}$ hor. mot.

\begin{tabular}{|c|c|c|c|}
\hline & in lat. & in lat. & latitude. \\
\hline$I^{\prime} 041^{\prime \prime}, 226$ & $247^{\prime \prime}, 44$ & $-128^{\prime \prime}, 72$ & $20 \quad 7,63$ \\
\hline 4041,212 & 247,02 & 123,51 & 2131,35 \\
\hline 1041,1 & 246,72 & 123,36 & 22.5 \\
\hline 4041 , & 246,54 & 123,27 & 241 \\
\hline 1041 & 246,48 & 123,24 & 2541,49 \\
\hline 404 & 246,42 & 123,21 & 274 \\
\hline 1041 , & 246,24 & 123,12 & 2827 , \\
\hline 4041 & 245 , & 122 , & 2950,79 \\
\hline 4 & 245 , & 122,76 & 311 \\
\hline & 244 & 122,49 & 32 \\
\hline 04 & 244,32 & 122,16 & 3358,2 \\
\hline
\end{tabular}

Conj. 21041,17

24041,156

$3 \quad 1041,142$

$340 \quad 41,128$

41041,114

$5 \quad 1041,086$

Sun's longitude.

Sun's $\boldsymbol{A R}$.

Apparent time.

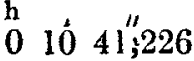

$040 \quad 41,212$

543 íf 300,71

$\begin{array}{lll}54 & 38 & 42,935\end{array}$

11041,198

14041,184

Conj. 21041,17

$\begin{array}{llll}2 & 40 & 4 \mathrm{l}, 156\end{array}$

$\begin{array}{llll}3 & 10 & 41,142\end{array}$

$\begin{array}{lll}340 & 41,128\end{array}$

41041,114

$440 \cdot 41,1$

$5 \quad 10 \quad 41,086$

$\begin{array}{lll}54 & 39 & 55,16\end{array}$

$\begin{array}{lll}54 & 41 & 7,385\end{array}$

$54 \quad 42 \quad 19,61$

$5443 \quad 31,835$

$5444 \quad 44,06$

$54 \quad 45 \quad 56,285$

$\begin{array}{lll}54 & 47 & 8,51\end{array}$

$\begin{array}{llll}54 & 48 & 20,735\end{array}$

$\begin{array}{llll}54 & 49 & 32,96\end{array}$

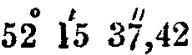

$\begin{array}{llll}52 & 16 & 51,48\end{array}$

$\begin{array}{lll}52 & 18 & 5,54\end{array}$

$\begin{array}{llll}52 & 19 & 19,6\end{array}$

$\begin{array}{lll}52 & 20 & 33,66\end{array}$

$\begin{array}{lll}52 & 21 & 47,72\end{array}$

$\begin{array}{lll}52 & 23 & 1,78\end{array}$

$\begin{array}{llll}52 & 24 & 15,84\end{array}$

52 $25: 29,9$

522643,96

$52 \quad 27 \quad 58,02$

Sun's half hourly motion in longitude, .. $1^{\prime} 12^{\prime \prime}, 225$

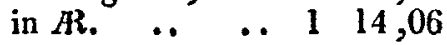


In procuring the preceding table of general data, I have used the method given by Professor Vince in his Astronomy, vol. iii. p. 52, for finding the horary motions in longitude and latitude, before and after the time for which the places are calculated. Mr. Vince remarks that this method is not perfectly correct, but sufficiently so for the longest eclipse. I am inclined to think it far from probable, that in any case, even when the moon is in her perigee, the half hourly change of her motion can vary in four hours in the ratio of $3,5,7,9$. In the example given by $\mathrm{Mr}$. Vince, the equation of the second order in longitude is $1^{\prime \prime} \cdot 24$; from which, applying the arithmetical progression, we find that the horary motion at two hours preceding, is increased by $11^{\prime \prime} \cdot 16$, and, at two hours following, diminished by the same quantity. Now, suppose the instant for which the places are calculated from the tables, to be an hour before the moon is in perigee; the horary motion will in this case increase for the first hour which follows, and then, having arrived at its maximum, it will begin to decrease. In such a case, therefore, I am at a loss to see how the above method could hold good.

I have been induced to solicit the attention of your valuable correspondents to this point, from a hope that some of them will have the goodness to give, through the medium of your Magazine, some easy, and at the same time more accurate method of applying the equation of the second order, both in longitude and latitude.

The following table exhibits the results of the principal steps of the calculations for Greenwich and Edinburgh. The times marked on the tops of the columns are the instants assumed.

The line marked $\odot$ contains the Sun's longitude.

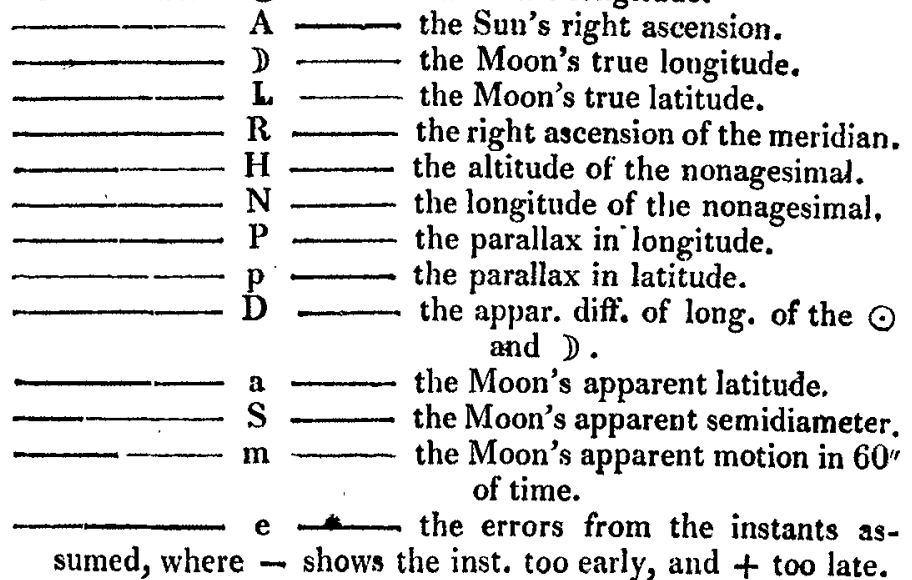




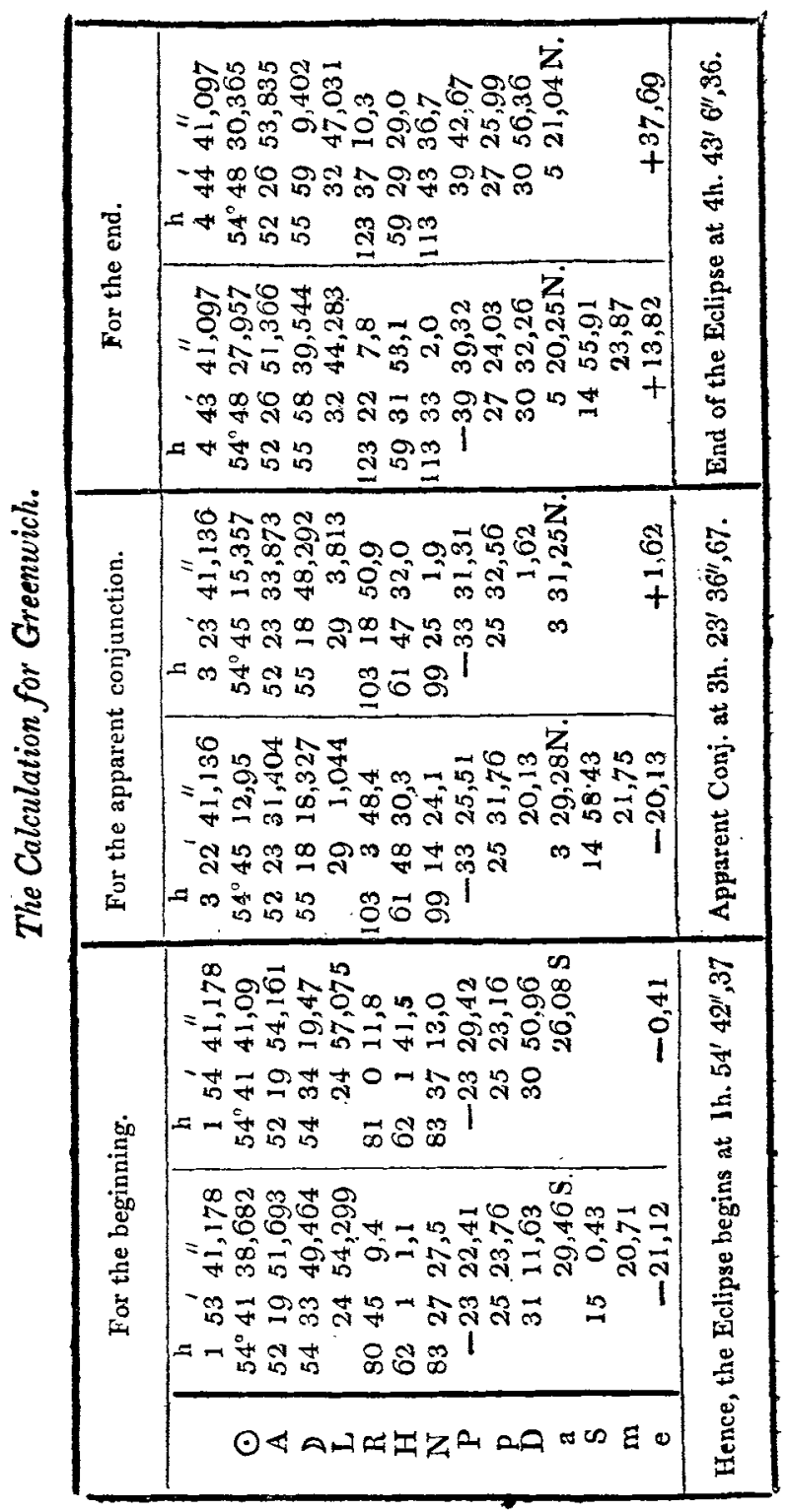


which will happen on the 15 th of May 1836.

\begin{tabular}{|c|c|c|}
\hline \multirow{2}{*}{ 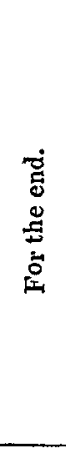 } & 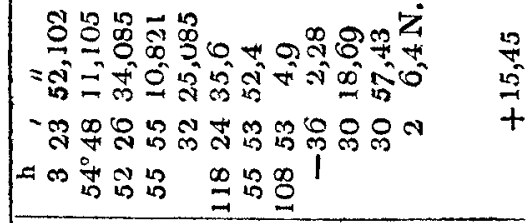 & 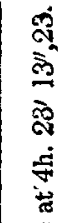 \\
\hline & 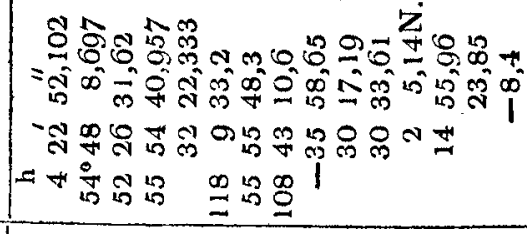 & 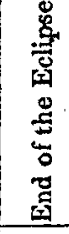 \\
\hline \multirow{3}{*}{ 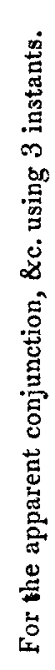 } & 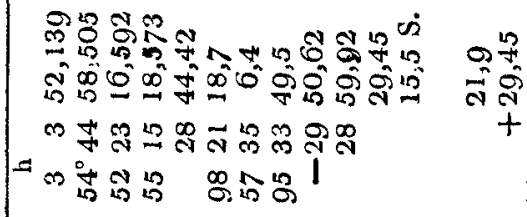 & 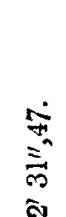 \\
\hline & 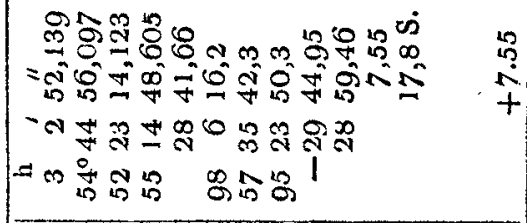 & 窇 \\
\hline & 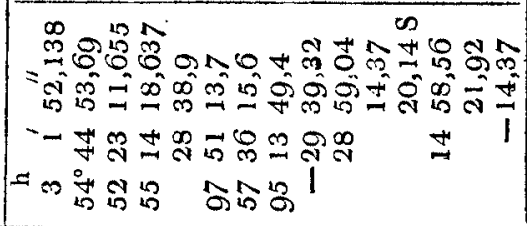 & 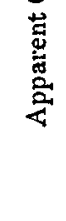 \\
\hline \multirow{3}{*}{ 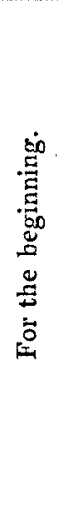 } & 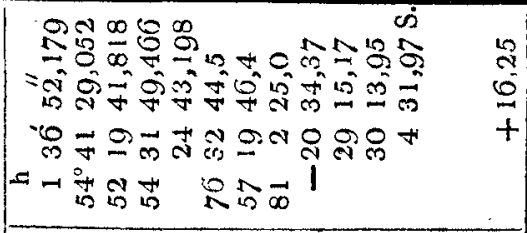 & 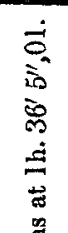 \\
\hline & 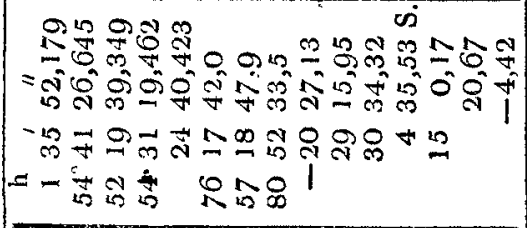 & 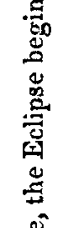 \\
\hline & $\odot く$ & $\stackrel{ \pm}{ \pm}$ \\
\hline
\end{tabular}


The other results may now be readily obtained, and in one view they are as follows, apparent time:

\section{At Grisnwich}

The eclipse begins at $\quad . . \quad \ldots \quad \ldots \quad \ldots 1^{\text {h }} 54^{\prime} 42^{\prime \prime}, 37$ P.M.

Greastest obscuration, $\quad$..

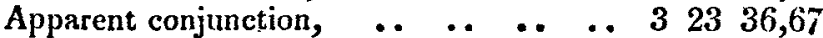

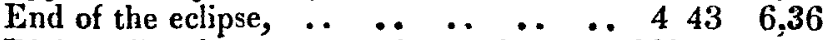

Digits eclipsed at greatest obscuration, $10^{\circ} 28 \quad 58,45$ on the north part of the sun's disc.

The moon will make the first impression on the sun's disc at $131^{\circ} 39^{\prime}$ from his vertex on the right hand.

\section{At Edinburgh}

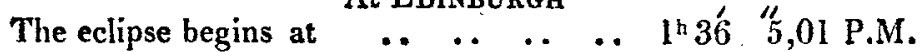

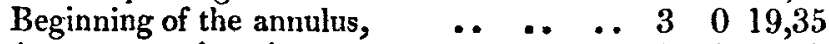

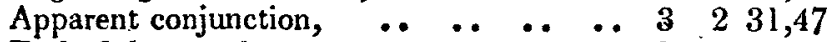

End of the annulus, $\quad$..

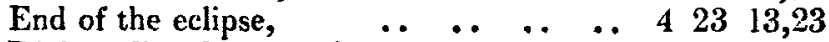

Digits eclipsed during the annulus, .. $11^{\circ} 3320,74$

Breadth of the annulus on the sun's north limb, 110,36

Proportion of the sun's disc obscured during the

33,14

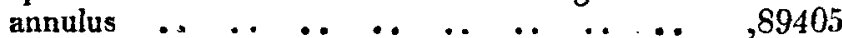

The moon will make the first impression on the sun's disc at $132 \cdot 22 \frac{1}{2}$ from his vertex on the right hand.

As I am anxious to determine the error of the Astronomioal Tables by means of the observations made on the late solar eclipse, I should be much obliged to you, or Dr. Burney, to communicate, through your Magazine, the latitude and longitude of Dr. Burney's Observatory at Gosport.

I am, dear sir, yours respectfully,

To Dr. Tilloch.

Geo. Inses.

VII. Remarks on Mr. RiDDLE's Claim to the Invention of a new Method of determining the Latitude.

A Edinburgh, June 8, 1821.

SIR, - As an article by Mr. Edward Riddle has been inserted in the Philosophical Magazine for May 182I, which appears to me to contain insinuations totally unfounded, I beg leave to say a few words in reply.

General Brisbane having been abroad for some time expresses himself as follows, in his Memoir on the Repeating Circle, Edinburgh Philosophical Transactions, vol, ix. Part I. page 97, \&c. and read in February 1819.

"Having' 


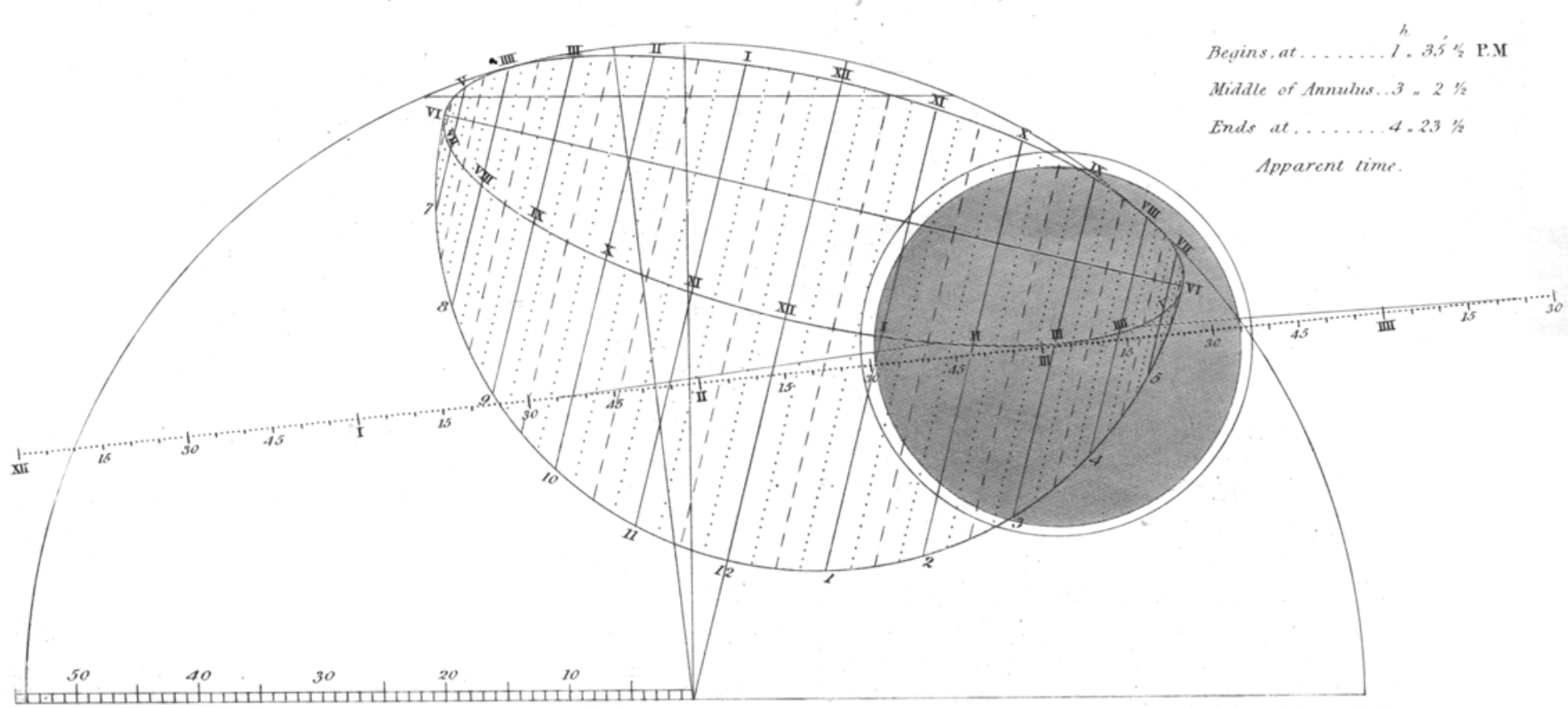

